\title{
A Lateral Salt Bridge for the Specific Assembly of an ABC-Type Collagen Heterotrimer
}

\section{Journal Article}

\section{Author(s):}

Hentzen, Nina B.; Islami, Valdrin; Köhler, Martin; Zenobi, Renato (D); Wennemers, Helma

Publication date:

2020-02-05

Permanent link:

https://doi.org/10.3929/ethz-b-000399332

Rights / license:

In Copyright - Non-Commercial Use Permitted

Originally published in:

Journal of the American Chemical Society 142(5), https://doi.org/10.1021/jacs.9b13037

Funding acknowledgement:

178805 - Synthetic Collagen (Fortsetzung) (SNF)

178765 - Soft ionization mass spectrometry for studying noncovalent interactions (SNF) 


\title{
A Lateral Salt Bridge for the Specific Assembly of an ABC-Type Collagen Heterotrimer
}

\author{
Nina B. Hentzen, Valdrin Islami, Martin Köhler, Renato Zenobi, and Helma Wennemers* \\ Laboratory of Organic Chemistry, ETH Zurich, D-CHAB, Vladimir-Prelog-Weg 3, 8093, Zurich, Switzerland
}

\begin{abstract}
Nature uses salt bridges to control the folding and stability of many proteins, including collagen, the key structural protein in mammals. Here, we present an interstrand salt bridge between (4S)-aminoproline (Amp) and aspartic acid (Asp) that directs the composition and register-specific assembly of synthetic collagen heterotrimers. This Amp-Asp salt bridge allowed for the rational design of strands that fold into $\mathrm{A}_{2} \mathrm{~B}$ and $\mathrm{ABC}$-type heterotrimers with only three salt bridges per triple helix. Native ESI-MS and NMR spectroscopic analyses corroborated the specific assembly of the ABC heterotrimer.
\end{abstract}

Collagen is an abundant protein in mammals that is responsible for mechanical stability and cell signaling in connective tissue. ${ }^{1}$ Natural collagen triple helices are composed of three identical or of up to three different strands. ${ }^{2}$ The structural diversity of these homo- and heterotrimers is central for the numerous functions of collagen. ${ }^{1,3}$ Synthetic collagen peptides with tailored selfassembly properties are attractive for applications in tissue engineering and wound healing. ${ }^{4}$ Whereas the selfassembly of collagen mimetic peptides (CMPs) into homotrimers is straightforward, the design of heterotrimers composed of two $\left(\mathrm{A}_{2} \mathrm{~B}\right)$ or three $(\mathrm{ABC})$ different strands is challenging and only few examples have been reported; most rely on electrostatic interactions, for example, between lysine and aspartic acid residues. ${ }^{5-8}$

Collagen comprises three polyproline II (PPII)-like strands that consist of repeating Xaa-Yaa-Gly units with proline (Pro, P) and (4R)-hydroxyproline (Hyp, O) as the most common residues in the Xaa and Yaa positions, respectively (Figure 1). ${ }^{1,9} \mathrm{~A}$ high content of these canonical proline residues favors preorganization of the strands into PPII helices and stabilizes the triple helix. Hydrogen bonds between the glycine $\mathrm{N}-\mathrm{H}$ and the carbonyl $\mathrm{O}$ of the neighboring proline residue further stabilize the triple helix. The single strands assemble with a one-residue stagger that creates a leading, a middle, and a lagging strand and defines the register of the triple helix. ${ }^{1,5,10}$

The formation of ABC-type collagen heterotrimers from three different strands is challenging since a total of $3^{3}=27$ trimers that differ in their composition and register can form. Nature ensures correct chain association by a a)
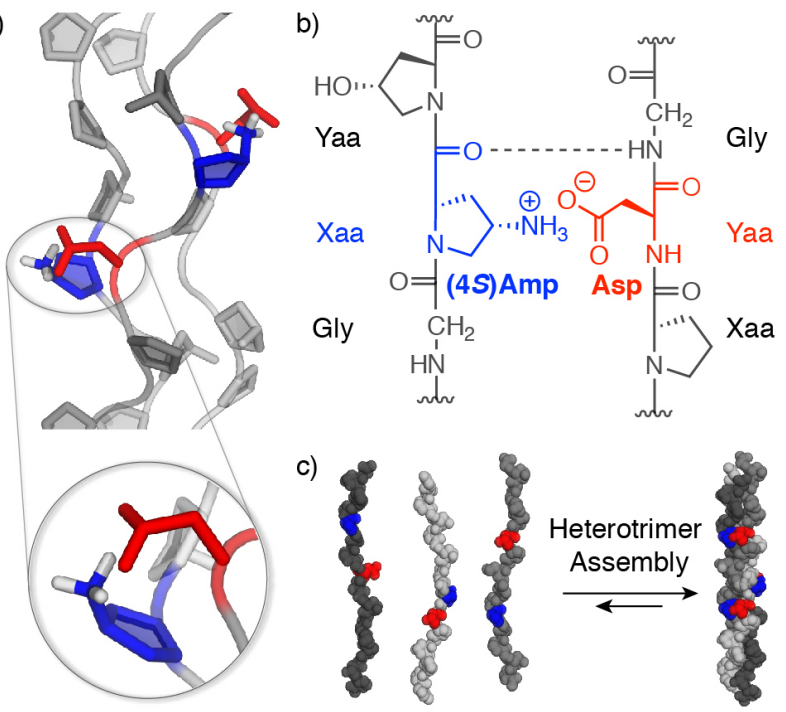

Figure 1. a) Model of a collagen triple helix with (4S)Amp in Xaa (blue) and Asp in Yaa (red) of neighboring strands (adapted from pdb 3B0S). b) Structure of two collagen strands with (4S)Amp and Asp residues. c) Assembly of an ABC-type heterotrimer with three salt bridges between (4S)Amp and Asp residues.

disulfide-mediated trimerization of C-propeptide domains. ${ }^{11}$ Synthetic heterotrimer formation requires residues that selectively interact with each other in adjacent strands and do not disturb the native PPII-helical conformation of the CMPs.

Previous studies used interstrand electrostatic interactions between lysine (Lys, K) and aspartic acid (Asp, D) residues for the formation of synthetic heterotrimers. ${ }^{6,8}$ The geometric preference of this salt bridge is, however, not well defined since the Lys side chain is conformationally flexible. As a result, Lys and Asp can either pair parallel or perpendicularly to the helix axis to form so-called axial or lateral salt bridges between the ammonium and carboxylate groups. ${ }^{8}$ In addition, the exposure of the charged moieties in the extended side chains to surrounding water weakens the salt bridge. ${ }^{8,12}$ As a result, specific triple helix formation requires multiple Lys-Asp salt bridges and therefore substitution of typically one third of the canonical Pro by Lys and Asp residues. ${ }^{6,8}$ Replacement of Pro residues reduces, however, the preorganization of the strands into PPII helices and leaves little room for further structural modifications. 
Here, we present the assembly of collagen heterotrimers based on a geometrically well-defined salt bridge between (4S)-aminoproline (Amp, X) in the Xaa and Asp in the coplanar Yaa position of neighboring strands (Figure 1). This directional interaction was utilized for the rational design of strands that assemble exclusively into the target heterotrimers. A 24-mer ABC-type heterotrimer was assembled by the formation of only three salt bridges.

Recently we showed that a protonated (4S)Amp residue in the Xaa position destabilizes the collagen triple helix by formation of a transannular $\mathrm{H}$-bond, which competes with the H-bond between two collagen strands. ${ }^{13,14} \mathrm{We}$ hypothesized that an Asp residue in the coplanar Yaa position of a neighboring strand could engage the ammonium group of (4S)Amp in an interstrand salt bridge (Figure 1a/b). This should weaken the transannular H-bond and relieve the Coulombic repulsion between proximal ammonium groups, thereby stabilizing the triple helix. Molecular modeling of the charged pair in the triple helix predicts a distance of $2.6 \AA$ between the ammonium and carboxylate groups $\left(\mathrm{N}^{+}-\mathrm{O}^{-}\right)$and a $\mathrm{H}-$ bond length of $1.7 \AA$, geometries that are ideal for a strong salt bridge (Figure S9). ${ }^{12}$ We also reasoned that positioning of (4S)Amp and Asp such that complementary salt bridges can only form upon assembly of different strands should enable specific heterotrimer formation. Further, since unpaired (4S)Amp in Xaa destabilizes triple helices, this design should favor the desired heterotrimer over competing assemblies.

We started to examine the envisioned Amp-Asp salt bridge by preparing and studying the stability of triple helices derived from CMP 1 that contains (4S)Amp-AspGly as the middle repeat unit of a 21-mer (Figure 2a). This peptide should form a homotrimer containing two AmpAsp salt bridges and two unpaired charges (Figure 2b). We also prepared CMPs 2-4 bearing only (4S)Amp (CMP 2), Asp (CMP 3) and a glutamic acid (Glu) residue in place of Asp (CMP 4) (Figure 2a). CD spectra of CMP 1-4 in phosphate buffer $(50 \mathrm{mM}, \mathrm{pH}$ 7.2) show the typical signature of the collagen triple helix (minimum at $\sim 200$ $\mathrm{nm}$, maximum at $225 \mathrm{~nm}$; Figure S1). Thermal denaturation studies using CD spectroscopy as a monitoring tool provided sigmoidal denaturation curves (Figure S2) with midpoint transitions (melting temperature, $T_{\mathrm{m}}$ ) that reflect the relative stability of the triple helices. The triple helix of CMP 1 has a $T_{\mathrm{m}}$ of $30{ }^{\circ} \mathrm{C}$ whereas the stability of all other trimers is lower (Figure 2a). The lower melting temperatures of triple helical CMP $2\left(T_{\mathrm{m}}=27^{\circ} \mathrm{C}\right)$ and CMP $3\left(T_{\mathrm{m}}=24^{\circ} \mathrm{C}\right)$ confirm that unpaired (4S)Amp and Asp residues destabilize the triple helix. ${ }^{15}$ The stability of triple helical CMP 4 is even lower $\left(T_{\mathrm{m}}=22{ }^{\circ} \mathrm{C}\right)$ highlighting that the additional methylene group of Glu precludes a stabilizing interaction with (4S)Amp. This result corroborates that the spatial arrangement of (4S)Amp in the Xaa and Asp in the Yaa position enables a stabilizing interstrand salt bridge. a)

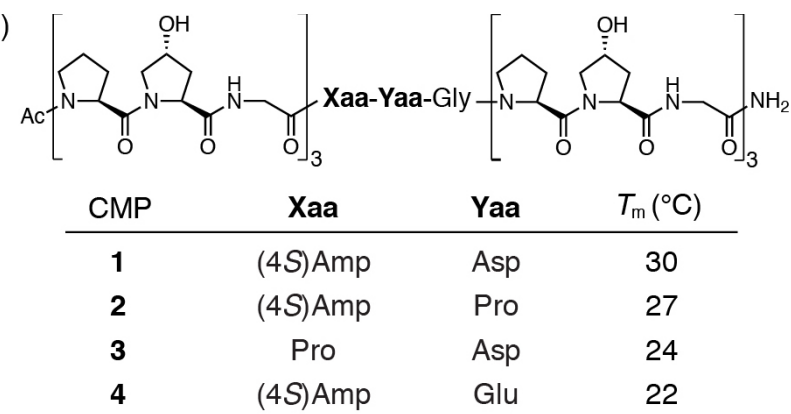

b)

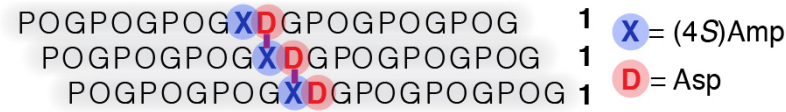

c)

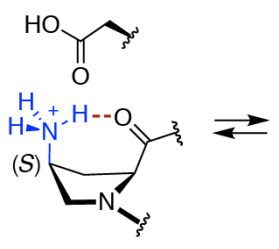

$\mathrm{pH} 3$

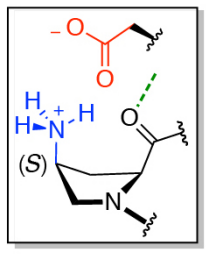

$\mathrm{pH} 7$

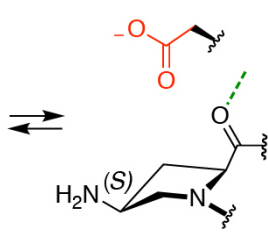

$\mathrm{pH} 11$
$T_{\mathrm{m}}=26^{\circ} \mathrm{C}$

$T_{\mathrm{m}}=30^{\circ} \mathrm{C}$

$T_{\mathrm{m}}=25^{\circ} \mathrm{C}$

Figure 2. a) $T_{\mathrm{m}}$ values of the triple helices formed by CMPs 1-4 as determined by thermal denaturation studies at $\mathrm{pH} 7.2(200 \mu \mathrm{M}$ in $50 \mathrm{mM}$ phosphate buffer, heating rate of $1{ }^{\circ} \mathrm{C} / 100 \mathrm{~s}$, value of CMP 2 from ref. 13a). b) Homotrimer of CMP 1. Salt bridges between (4S)Amp and Asp are indicated by a purple line. c) Protonation states of $(4 S) \mathrm{Amp}$ and Asp at different $\mathrm{pH}$. At acidic $\mathrm{pH}$, a transannular H-bond (red dashes) competes with the interstrand $\mathrm{H}$-bond (green dashes).

We further probed the Amp-Asp salt bridge by determining the stability of the homotrimer of CMP 1 in acidic and basic solutions. We reasoned that protonation of the carboxylate of Asp should reduce the strength of the Amp-Asp interaction. The resulting unpaired protonated (4S)Amp should destabilize the triple helix (Figure 2c, left). Indeed, the stability of the homotrimer is reduced $\left(T_{\mathrm{m}}\right.$ $=26{ }^{\circ} \mathrm{C}$ ) at $\mathrm{pH} 3$. The stability of the triple helix is also lower at $\mathrm{pH} 11\left(T_{\mathrm{m}}=25^{\circ} \mathrm{C}\right.$; Figure $2 \mathrm{c}$, right $)$, which is in agreement with a neutral (4S)Amp and repulsion by the carboxylate groups of the Asp residues as observed for CMP 3.

Next we investigated whether the Amp-Asp pair allows for formation of $\mathrm{A}_{2} \mathrm{~B}$ heterotrimers. We designed CMP 5 to complement the charges of two strands of CMP 1 and thereby serve as the leading strand in a $\mathbf{5 \cdot 1 \cdot 1}$ heterotrimer (Figure 3a). The homotrimer of CMP 5 would feature only one salt bridge and four unpaired charged moieties. This homotrimer should therefore be less stable than the homotrimer of CMP 1 with two salt bridges and two unpaired charges (Figure 3a). Heterotrimer $\mathbf{5 \cdot 1 \cdot 1}$ in which every charged residue would be paired should be favored over the $\mathbf{1 \cdot 1} \cdot 1$ and $\mathbf{5 \cdot 5 \cdot 5}$ homotrimers. To allow for distinction of CMPs $\mathbf{1}$ and $\mathbf{5}$ by mass spectrometry a Hyp residue was replaced by Pro in CMP 5. 
CMP 1: Ac-[POG $]_{3}-X D G-P O G-[P O G]_{2}-\mathrm{NH}_{2}$ $M=1946.88 \mathrm{Da}$ CMP 5: AC-[POG $]_{3}-\mathrm{PDG}-\mathrm{XPG}-[\mathrm{POG}]_{2}-\mathrm{NH}_{2}$ $\mathrm{M}=1930.88 \mathrm{Da}$

a)

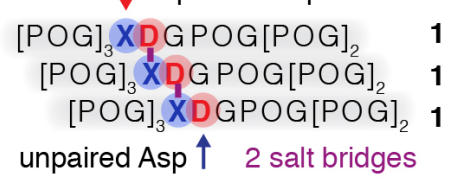

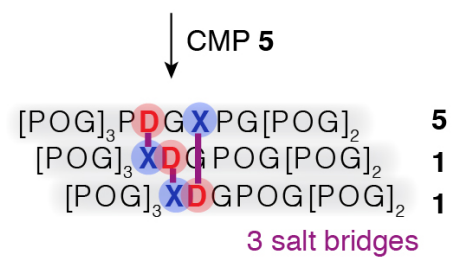

$\begin{array}{cc}\mathrm{POG}_{3} \mathrm{PDG} \times \mathrm{PG}[\mathrm{POG}]_{2} & \mathbf{5} \\ {[\mathrm{POG}]_{3} \mathrm{PD} \times \mathbf{X G}[\mathrm{POG}]_{2}} & \mathbf{5} \\ {[\mathrm{POG}]_{3} \mathrm{PDG} \times \mathrm{PG}[\mathrm{POG}]_{2}} & \mathbf{5} \\ \text { 1 salt bridge } & \end{array}$

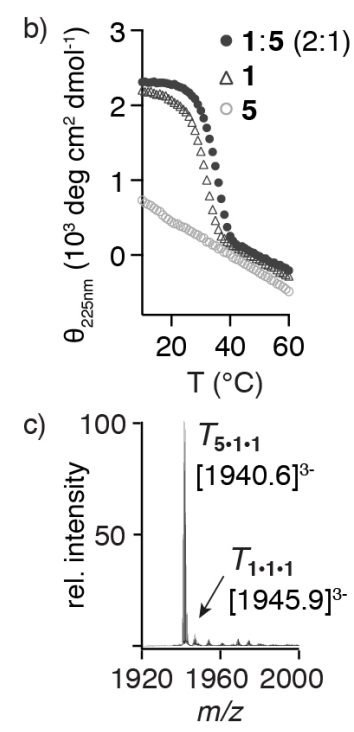

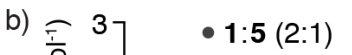

Figure 3. a) Assembly of CMPs 1 and 5 into $A_{2} B$ heterotrimer $\mathbf{5} \cdot \mathbf{1} \cdot \mathbf{1}$ and homotrimers $\mathbf{1} \cdot \mathbf{1} \cdot \mathbf{1}$ and $\mathbf{5} \cdot \mathbf{5} \cdot \mathbf{5}$. b) Thermal denaturation of CMPs $\mathbf{1}, \mathbf{5}$ and a $2: 1$ mixture $(200 \mu \mathrm{M}$ in $50 \mathrm{mM}$ phosphate buffer, $\mathrm{pH}$ 7.2). c) Native ESI-MS of CMPs 1 and $\mathbf{5}(2: 1 ; 50 \mu \mathrm{M}$ in $100 \mathrm{mM}$ aq. $\mathrm{NH}_{4} \mathrm{Ac}, \mathrm{pH} 5.0$ ).

CMP 5 does indeed not form homotrimers as indicated by the essentially linear thermal denaturation curve (Figure 3b). For an annealed 2:1 mixture of CMPs $\mathbf{1}$ and $\mathbf{5}$ we observed a $T_{\mathrm{m}}$ of $34{ }^{\circ} \mathrm{C}$. This value is $4{ }^{\circ} \mathrm{C}$ higher than that of the $\mathbf{1} \cdot \mathbf{1} \cdot \mathbf{1}$ homotrimer and indicates the formation of a more stable triple helix. The stability of the assembly was hardly affected by an increased salt concentration. ${ }^{16}$ To verify heterotrimer formation, we used native ESI-MS, a method we recently introduced as a tool to simultaneously monitor the composition and thermal stability of noncovalently assembled triple helices in mixtures of CMPs. ${ }^{17}$ Native ESI-MS analysis of the 2:1 mixture of CMPs 1 and 5 revealed a signal at $\mathrm{m} / \mathrm{z}=1940.6$, which corresponds to the $\mathbf{5} \cdot \mathbf{1} \cdot \mathbf{1}$ heterotrimer $\left([\mathrm{M}-3 \mathrm{H}]^{3-}\right.$, Figure $\left.3 \mathrm{c}\right)$. Only a minor signal corresponding to the $\mathbf{1 \cdot 1 \cdot 1}$ homotrimer was detected. ${ }^{18}$ In a control experiment, we also subjected a 2:1 mixture of CMP 4 and CMP 5 to native ESI-MS analysis (Figure S6). Only tiny signals corresponding to trimers were detected in this mixture, confirming that Asp, but not Glu, enables heterotrimer formation.

Finally, we probed whether the Amp-Asp salt bridge even enables the formation of an $\mathrm{ABC}$ heterotrimer from a mixture of three different strands. We designed CMPs 6, 7, and $\mathbf{8}$ for the composition- and register-specific assembly into an $\mathrm{ABC}$ heterotrimer (Figure 4a). Each of these 24mer CMPs contains a (4S)Amp and an Asp residue. ${ }^{19}$ The charged residues were positioned such that a maximum of three salt bridges can only form in the target $\mathrm{ABC}$ triple helix with CMP 6 as the lead, CMP 7 as the middle and CMP 8 as the lag strand (6.7.8 heterotrimer, Figure $4 a)$. Alternative homo- or heterotrimeric combinations of the strands would contain unpaired charged residues and should therefore be significantly less stable than heterotrimer 6.7.8 (Figures S10 and S11). ${ }^{15} \mathrm{~N}$-labelled Gly was introduced in the coplanar position of each charged pair in the expected $\mathbf{6 \cdot 7 \cdot 8}$ triple helix to allow for analyzing heterotrimer formation by NMR spectroscopy. Mass distinction of the CMPs was achieved by replacing Hyp with Pro residues and/or by capping the peptides with propionyl instead of acetyl groups.

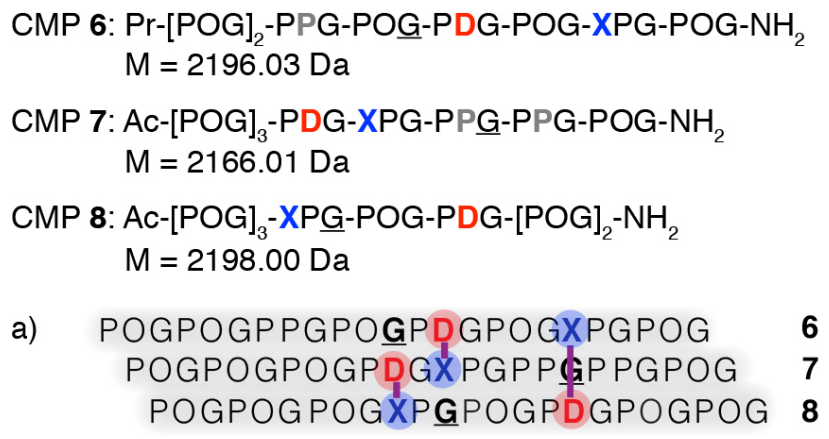

b)
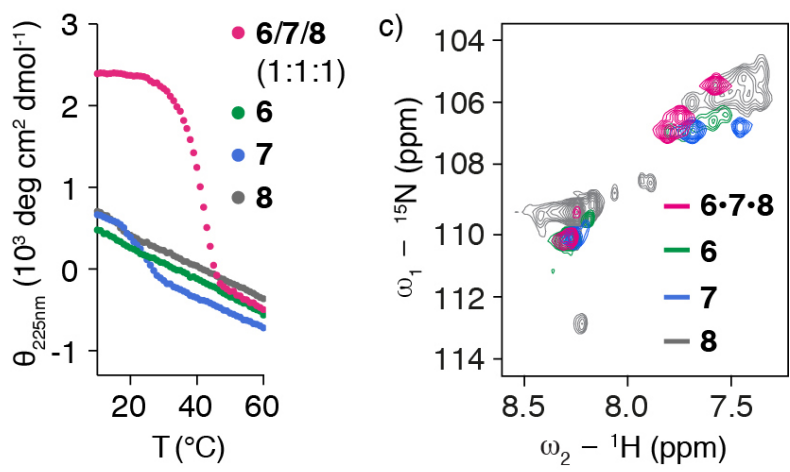

d)

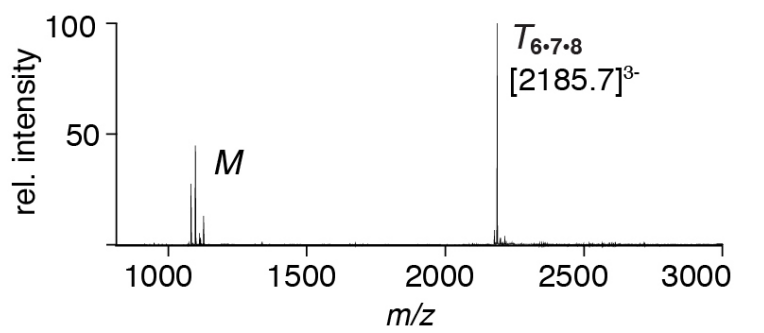

Figure 4. a) $\mathrm{ABC}$ heterotrimer formed by CMPs 6-8 $(\mathrm{Pr}=\mathrm{Et}-\mathrm{CO}$, $\underline{\mathrm{G}}={ }^{15} \mathrm{~N}-\mathrm{Gly}$ ) b) Thermal denaturation of CMPs $6-\mathbf{8}$ and their $1: 1: 1$ mixture $(200 \mu \mathrm{M}$ in $50 \mathrm{mM}$ phosphate buffer, $\mathrm{pH} 7.2)$. c) ${ }^{1} \mathrm{H}^{15}{ }^{15} \mathrm{~N}$ HQC spectra of CMPs $\mathbf{6}-\mathbf{8}$ and their $1: 1: 1$ mixture (3.3 $\mathrm{mM}$ in $9: 1 \mathrm{H}_{2} \mathrm{O} / \mathrm{D}_{2} \mathrm{O}$ at $\left.\mathrm{pH} \sim 6\right)$. d) Native ESI-MS of a $1: 1: 1$ mixture of CMPs 6-8 (50 $\mu \mathrm{M}$ in $100 \mathrm{mM}$ aq. $\left.\mathrm{NH}_{4} \mathrm{Ac}, \mathrm{pH} 5.0\right)$.

Thermal denaturation studies with CMPs 6 and 8 showed that these peptides do not self-assemble into homotrimers (Figure 4b, green and gray). Only CMP 7 forms a homotrimer, which has, however, a low thermal stability $\left(T_{\mathrm{m}}=23^{\circ} \mathrm{C}\right.$; Figure $4 \mathrm{~b}$, blue), in agreement with the presence of only one salt bridge (Figure S11). In contrast, an annealed 1:1:1 mixture of CMPs $\mathbf{6}, \mathbf{7}$, and 8 exhibited a sigmoidal unfolding curve with a $T_{\mathrm{m}}$ value of $40{ }^{\circ} \mathrm{C}$, a finding that indicates heterotrimer formation (Figure 4b, magenta). Native ESI-MS analysis of the mixture revealed a signal at $\mathrm{m} / \mathrm{z}=2185.7$ that corresponds 
to the expected $\mathbf{6 \cdot 7 \cdot 8}$ heterotrimer (Figure $4 d$ ). Other collagen trimers are not detectable and the only other visible signals correspond to monomeric CMPs 6-8. These results demonstrate the exclusive formation of a heterotrimer composed of CMPs 6, 7, and 8 out of the mixture of the three different CMPs. To further analyze the specificity of the heterotrimer formation we recorded ${ }^{1} \mathrm{H}$ ${ }^{15} \mathrm{~N}$ HSQC spectra of the annealed equimolar mixture of CMPs 6, 7, and 8 and of the individual peptides at $4{ }^{\circ} \mathrm{C}$ (Figure 4c). We also recorded a spectrum of the 1:1:1 mixture at $70{ }^{\circ} \mathrm{C}$ to identify the signals that correspond to triple helices (7.9-7.2 ppm) and monomers (8.5-8.0 ppm; Figure S7). Three unique signals are visible in the "trimer region" of the spectrum of the 1:1:1 mixture (Figure $4 \mathrm{c}$, magenta) that do not occur in the spectra of the individual peptides (Figure 4c, green, blue, gray). This finding corroborates the specific assembly of CMPs 6-8 into only one $\mathrm{ABC}$ heterotrimer with a defined composition and register.

In conclusion, we introduced the Amp-Asp pair in coplanar Xaa and Yaa positions of neighboring strands as a new tool for the specific assembly of heterotrimeric collagen triple helices. As little as three salt bridges are sufficient to assemble 24-mers into an ABC-type heterotrimer with control over its composition and register. Unpaired (4S)Amp and Asp residues disfavor triple helix formation and preclude undesired assemblies. Thus, specific heterotrimer formation only occurs when the Amp and Asp residues are paired in coplanar Xaa and Yaa positions. The Amp-Asp salt bridge therefore provides a versatile tool for the design of tailored collagen structures.

\section{ASSOCIATED CONTENT}

Supporting Information. Details on the syntheses and analyses of the presented compounds. This material is available free of charge via the Internet at http://pubs.acs.org.

\section{AUTHOR INFORMATION}

\section{Corresponding Author}

*Helma.Wennemers@org.chem.ethz.ch

\section{ORCID}

Helma Wennemers: 0000-0002-3075-5741

Nina B. Hentzen: 0000-0003-1038-7424

Martin Köhler: 0000-0002-0644-4281

Renato Zenobi: 0000-0001-5211-4358

\section{Notes}

The authors declare no competing financial interest.

\section{ACKNOWLEDGMENT}

N.H. is grateful for an AFR Ph.D. Fellowship from the Fonds National de la Recherche Luxembourg (FNR). This research was supported by the Swiss National Science Foundation (SNF grants 2000020 178805 (H.W.), 200020_178765 (R.Z.)). We thank Dr. Marc-Olivier Ebert and the NMR service of the Laboratory of Organic
Chemistry for recording NMR spectra and Dr. Matthew Aronoff for valuable comments on the manuscript.

\section{REFERENCES}

(1) (a) Shoulders, M. D.; Raines, R. T. Collagen structure and stability. Annu. Rev. Biochem. 2009, 78, 929-958. (b) Bella, J. Collagen structure: new tricks from a very old dog. Biochem. J. 2016, 473, 1001-1025. (c) Leitinger, B. Transmembrane collagen receptors. Annu. Rev. Cell Dev. Biol. 2011, 27, 265-290.

(2) (a) Ricard-Blum, S. The collagen family. Cold Spring Harb. Perspect. Biol. 2011, 3, a004978. (b) Bella, J.; Hulmes, D. J. S. Fibrillar collagens. Subcellular Biochemistry 2017, 82, 457-490.

(3) (a) Hynes, R. O.; Naba, A. Overview of the matrisome - an inventory of extracellular matrix constituents and functions. Cold Spring Harb. Perspect. Biol. 2012, 4, a004903. For selected examples, see: (b) Emsley, J.; Knight, C. G.; Farndale, R. W.; Barnes, M. J.; Liddington, R. C. Structural basis of collagen recognition by integrin alpha2beta1. Cell 2000, 101, 47-56. (c) Sacca, B; Moroder, L. Synthesis of heterotrimeric collagen peptides containing the alpha1beta1 integrin recognition site of collagen type IV. J. Pept. Sci., 2002, 8, 192-204.

(4) (a) Fields, G. B. Synthesis and biological applications of collagen-model triple-helical peptides. Org. Biomol. Chem. 2010, 8, 1237-1258. (b) Chattopadhyay, S.; Raines, R. T. Collagen-based biomaterials for wound healing. Biopolymers 2014, 101, 821-833. (c) An, B.; Lin, Y.-S.; Brodsky, B. Collagen interactions: Drug design and delivery. Adv. Drug Deliv. Rev. 2016, 97, 69-84. (d) Strauss, K.; Chmielewski, J. Advances in the design and higher-order assembly of collagen mimetic peptides for regenerative medicine. Curr. Opin. Biotechnol. 2017, 46, 34-41.

(5) (a) Jalan, A. A.; Hartgerink, J. D. Pairwise interactions in collagen and the design of heterotrimeric helices. Curr. Opin. Chem. Biol. 2013, 17, 960-967. (b) Fallas, J. A.; O'Leary, L. E. R.; Hartgerink, J. D. Synthetic collagen mimics: self-assembly of homotrimers, heterotrimers and higher order structures. Chem. Soc. Rev. 2010, 39, 3510-3527.

(6) (a) Persikov, A. V., Ramshaw, J. A. M., Kirkpatrick, A., Brodsky, B. Peptide investigations of pairwise interactions in the collagen triple-helix. J. Mol. Biol. 2002, 316, 385-394. (b) Gauba, V.; Hartgerink, J. D. Surprisingly high stability of collagen ABC heterotrimer: Evaluation of side chain charge pairs. J. Am. Chem. Soc. 2007, 129, 15034-15041. (c) Gauba, V.; Hartgerink, J. D. Selfassembled heterotrimeric collagen triple helices directed through electrostatic interactions. J. Am. Chem. Soc. 2007, 129, 2683-2690. (d) Russell, L. E.; Fallas, J. A.; Hartgerink, J. D. Selective assembly of a high stability AAB collagen heterotrimer. J. Am. Chem. Soc. 2010, 132, 3242-3243. (e) O'Leary, L. E. R.; Fallas, J. A.; Hartgerink, J. D. Positive and negative design leads to compositional control in AAB collagen heterotrimers. J. Am. Chem. Soc. 2011, 133, 54325443. (f) Sarkar, B.; O'Leary, L. E. R.; Hartgerink, J. D. Selfassembly of fiber-forming collagen mimetic peptides controlled by triple-helical nucleation. J. Am. Chem. Soc. 2014, 136, 14417-14424. (g) Tanrikulu, I. C.; Forticaux, A.; Jin, S.; Raines, R. T. Peptide tessellation yields micrometre-scale collagen triple helices. Nat. Chem. 2016, 8, 1008-1014.

(7) For examples of covalently linked collagen heterotrimers, see: (a) Kotch, F. W.; Raines, R.T. Self-assembly of synthetic collagen triple helices. Proc. Natl. Acad. Sci., U.S.A. 2006, 103, 3028-3033. (b) Boulègue, C.; Musiol, H. J.; Götz, M. G.; Renner, C.; Moroder, L. Natural and artificial cystine knots for assembly of homo- and heterotrimeric collagen models. Antioxid. Redox Signal. 2008, 10, 113-125. (c) Tanrikulu, I. C; Raines, R. T. Optimal Interstrand Bridges for Collagen-like Biomaterials. J. Am. Chem. Soc. 2014, 136 , 13490-13493. (d) Hentzen, N. B.; Smeenk, L. E. J.; Witek, J.; Riniker, S.; Wennemers, H. Cross-Linked Collagen Triple Helices by Oxime Ligation. J. Am. Chem. Soc. 2017, 139, 12815-12820. (e) Li, I. C.; Hulgan, S. A. H.; Walker, D. R.; Farndale, R. W.; Hartgerink, J. D.; Jalan, A. A. Covalent Capture of a Heterotrimeric Collagen Helix. Org. Lett. 2019, 21, 5480-5484.

(8) (a) Fallas, J. A., Dong, J., Tao, Y. J., Hartgerink, J. D. Structural 
insights into charge pair interactions in triple helical collagen-like proteins. J. Biol. Chem. 2012, 287, 8039-8047. (b) Wei, F., Fallas, J. A., Hartgerink, J. D. Sequence position and side chain length dependence of charge pair interactions in collagen triple helices. Macromol. Rapid Commun. 2012, 33, 1445-1452. (c) Zheng, H.; Lu, C.; Lan, J.; Fan, S.; Nanda, V.; Xu, F., How electrostatic networks modulate specificity and stability of collagen. Proc. Natl. Acad. Sci. U. S. A. 2018, 115, 6207-6212.

(9) Ramshaw, J. A.; Shah, N. K.; Brodsky, B. Gly-X-Y tripeptide frequencies in collagen: a context for host-guest triple-helical peptides. J. Struct. Biol. 1998, 122, 86-91.

(10) Bella, J.; Eaton, M.; Brodsky, B.; Berman, H. M. Crystal and molecular structure of a collagen-like peptide at 1.9 A resolution. Science 1994, 266, 75-81.

(11) (a) Boudko, S. P.; Bächinger, H. P. Structural insight for chain selection and stagger control in collagen. Sci. Rep. 2016, 6, 37831. (b) Sharma, U.; Carrique, L.; Vadon-Le Goff, S.; Mariano, N.; Georges, R. N.; Delolme, F.; Koivunen, P.; Myllyharju, J.; Moali, C.; Aghajari, N.; Hulmes, D. J. Structural basis of homo- and heterotrimerization of collagen I. Nat. Commun. 2017, 8, 14671. (c) DiChiara, A. S.; Li, R. C.; Suen, P. H.; Hosseini, A. S.; Taylor, R. J.; Weickhardt, A. F.; Malhotra, D.; McCaslin, D. R.; Shoulders, M. D. A cysteine-based molecular code informs collagen C-propeptide assembly. Nat. Commun. 2018, 9, 4206.

(12) (a) Kumar, S.; Nussinov, R. Close-range electrostatic interactions in proteins. ChemBioChem 2002, 3, 604-617. (b) Donald, J. E.; Kulp, D. W.; DeGrado, W. F. Salt bridges: Geometrically specific, designable interactions. Proteins Struct. Funct. Bioinforma. 2011, 79, 898-915.

(13) (a) Siebler, C.; Erdmann, R. S.; Wennemers, H. Switchable proline derivatives: tuning the conformational stability of the collagen triple helix by $\mathrm{pH}$ changes. Angew. Chem. Int. Ed. Engl. 2014, 53, 10340-10344. (b) Egli, J.; Siebler, C.; Maryasin, B.; Erdmann, R. S.; Bergande, C.; Ochsenfeld, C.; Wennemers, H. pH-Responsive aminoproline-containing collagen triple helices. Chem. - Eur. J. 2017, 23, 7938-7944.

(14) For a transannular H-bond in (4S)Hyp, see: Shoulders, M. D.; Kotch, F. W.; Choudhary, A.; Guzei, I. A.; Raines, R. T. The Aberrance of the $4 S$ Diastereomer of 4-Hydroxyproline. J. Am. Chem. Soc. 2010, 132, 10857-10865.

(15) Note, the homotrimer of Ac- $[\mathrm{POG}]_{7}-\mathrm{NH}_{2}$ has a $T_{\mathrm{m}}$ of $43{ }^{\circ} \mathrm{C}$ : Erdmann, R. S.; Wennemers, H. Importance of Ring Puckering versus Interstrand Hydrogen Bonds for the Conformational Stability of Collagen. Angew. Chem. Int. Ed. Engl. 2011, 50, 6835-6838.

(16) Note, experiments in different buffers (phosphate, PBS, $\mathrm{NH}_{4} \mathrm{Ac}$ ) and at different $\mathrm{pH}$ (5 and 7) provided the same $T_{\mathrm{m}}$ values, see the supporting information for details (Figure S3).

(17) Köhler, M.; Marchand, A.; Hentzen, N. B.; Egli, J.; Begley, A. I.; Wennemers, H.; Zenobi, R. Temperature-controlled electrospray ionization mass spectrometry as a tool to study collagen homo- and heterotrimers. Chem. Sci. 2019, 10, 9829-9835.

(18) Note, native ESI-MS distinguishes between triple helices of different composition, but not registry. The formation of $\mathbf{1 \cdot 5 \cdot 1}$ or $\mathbf{1 . 1} \mathbf{5}$ (leading/middle/lagging) heterotrimers is, however, unlikely since they would be held together by only one salt bridge (Figure S10).

(19) Note, we used 24-mer CMPs to access triple helices with higher stability compared to trimers formed by 21 -mers. 
Suggested Table of Content Graphic:

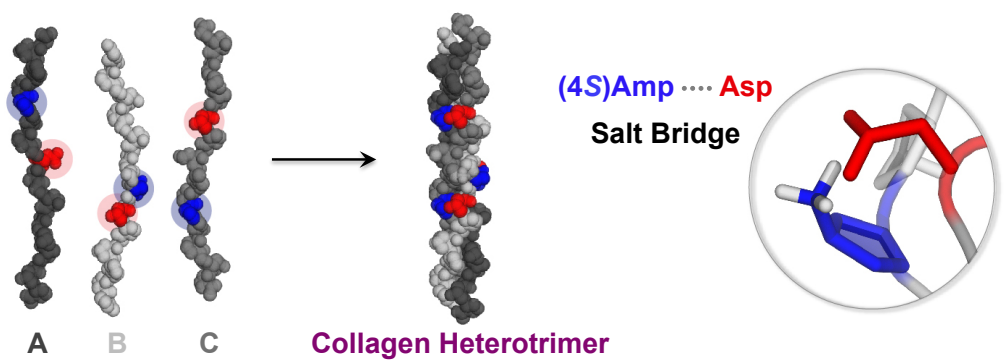

